\title{
Valor nutritivo do capim-braquiária no primeiro ano de recuperação com aplicações de nitrogênio e enxofre ${ }^{1}$
}

\section{Daniela Alves de Oliveira ${ }^{2}$, Edna Maria Bonfim-Silva ${ }^{3}$, Cristiane Prezotto Silveira ${ }^{4}$, Francisco Antonio Monteiro ${ }^{5}$}

\author{
1 Projeto apoiado pela FAPESP e pelo CNPq. \\ 2 Pós-graduanda em Solos e Nutrição de Plantas. Bolsista da CAPES. \\ ${ }^{3}$ Universidade Federal Rural de Pernambuco. \\ ${ }^{4}$ Pós-graduanda em Solos e Nutrição de Plantas, ESALQ-USP. Bolsista da FAPESP. \\ ${ }^{5}$ Departamento de Ciência do Solo, ESALQ-USP. Bolsista do CNPq.
}

RESUMO - Objetivou-se estudar a influência das combinações de doses de nitrogênio e de enxofre na recuperação de pastagens de capim-braquiária (Brachiaria decumbens) por meio da avaliação do valor nutritivo do capim nos períodos chuvoso e seco de um ano agrícola. O experimento foi realizado em pastagem degradada de capim-braquiária, num delineamento de blocos ao acaso, em fatorial $5 \times 5$, com cinco doses de nitrogênio $(0,150,300,450$ e $600 \mathrm{~kg} / \mathrm{ha} / \mathrm{ano})$ e cinco de enxofre $(0,15,30$, 45 e $60 \mathrm{~kg} / \mathrm{ha} / \mathrm{ano}$ ), com três repetições por combinação. As avaliações no campo foram realizadas a cada 35 dias no período das águas (de 21/12/2005 a 10/5/2006), totalizando cinco avaliações, e a cada 56 dias no período da seca (de 5/7/2006 a 25/10/2006), totalizando três avaliações. Os cortes das plantas a $10 \mathrm{~cm}$ da superfície do solo foram realizados em área delimitada de $0,25 \mathrm{~m}^{2}$. A combinação das doses de nitrogênio e de enxofre alterou as concentrações de proteína bruta, fibra em detergente neutro e fibra em detergente ácido na primeira avaliação do período seco. O nitrogênio foi o nutriente que mais influenciou no valor nutritivo do capim-braquiária, resultando em variações nas concentrações desses nutrientes e na digestibilidade in vitro da massa seca. O enxofre promove variação significativa na DIVMS no período chuvoso.

Palavras-chave: adubação, Brachiaria decumbens, digestibilidade, fibra, proteína

\section{Nutritional value of the Signal grass in the first year of recovery following nitrogen and sulphur applications}

\begin{abstract}
It was aimed to study the effects of combinations between nitrogen and sulphur rates for the recovery of Signal grass (Brachiara decumbens) pasture by evaluating the nutritional value during the wet and dry seasons in an agriculture year. The experiment was carried out in a degraded pasture of Signal grass, in a randomized block design, $5 \times 5$ factorial with five nitrogen rates $(0,150,300,450$ and $600 \mathrm{~kg} / \mathrm{ha} /$ year) and five sulphur rates $(0,15,30,45$ and $60 \mathrm{~kg} / \mathrm{ha} / \mathrm{year})$, with three replications per combination. Field evaluations were carried out every 35 days during the wet season (from December, $21^{\text {st }}$ 2005 to May, $10^{\text {th }}$ 2006), totalizing five evaluations, and at every 56 days during the dry season (July, $05^{\text {th }} 2006$ to October, $25^{\text {th }}$ 2006), with three evaluations. Plants were harvested at $10 \mathrm{~cm}$ height in a $0.25 \mathrm{~m}^{2}$ delimeted area. Combination of nitrogen and sulphur rates changed concentrations of crude protein, neutral detergent fiber and acid detergent fiber in the first evaluation of the dry season. Nitrogen is the nutrient that changed at most the nutritional values of the signal grass resulting in variations in concentrations of these nutrients and in the in vitro digestibility of dry mass. Sulphur provides significant change on in vitro digestibility of dry mass during the wet season.
\end{abstract}

Key Words: Brachiaria decumbens, digestibility, fertilization, fiber, protein

\section{Introdução}

Informações sobre pastagens cultivadas com plantas do gênero Brachiaria em diversas regiões do Brasil comprovam sinais de degradação (Boddey et al., 2004; Macedo, 2005). No estado de São Paulo, há anos já se tem descrito que a maior parte das pastagens de capim-braquiária encontra-se em estado de degradação (Soares Filho etal., 1992).
Pastagem degradada poderia ser definida como área com acentuada diminuição da produtividade agrícola (Dias-Filho, 2005) e consequente redução no valor nutritivo das plantas forrageiras.

Para a recuperação direta da pastagem, a adubação é indispensável, principalmente com nitrogênio, pois tem papel relevante nos casos de pastagens exclusivas de gramíneas forrageiras. O nitrogênio é o grande responsável

Recebido em 13/2/2008 e aprovado em 15/4/2009.

Correspondências devem ser enviadas para: danialves82@gmail.com 
pela alteração nas características nutricionais das gramíneas forrageiras e seu efeito é dependente do enxofre, pela relação entre esses nutrientes no metabolismo vegetal (Marschner, 1995).

O valor nutritivo é determinado pela composição química das plantas forrageiras, representada principalmente, pelos teores de proteína bruta (PB), fibra em detergente ácido (FDA) e fibra em detergente neutro (FDN) e pela digestibilidade in vitro da massa seca (Van Soest, 1994). A associação entre o valor nutritivo e o consumo voluntário de forragem pelo animal em pastejo define a qualidade da forrageira e afeta o desempenho e a produtividade animal em pastagens (Minson \& Wilson, 1994). Diversos estudos têm comprovado aumento significativo no valor nutritivo de plantas forrageiras com o suprimento de nitrogênio, porém a magnitude dessas respostas tem sido variada. Pode-se, assim, apontar que há necessidade de estudar doses de nitrogênio e a frequência do seu suprimento, combinadas com doses de enxofre, devido à participação conjunta do nitrogênio e do enxofre em diversos processos metabólicos.

Desse modo, objetivou-se estudar a influência das combinações de nitrogênio e enxofre na recuperação de pastagens de capim-braquiária e avaliar aspectos relacionados ao valor nutritivo desse capim nos períodos chuvoso e seco de um ano agrícola.

\section{Material e Métodos}

O experimento foi realizado na Agropecuária Rodomeu, localizada no distrito de Ibitiruna, município de Piracicaba, São Paulo (4757'56" longitude oeste; 2246'30" latitude sul), com altitude média de $600 \mathrm{~m}$ e clima, segundo classificação de Köppen, do tipo Cwa, tropical de altitude, com inverno seco e temperatura do mês mais quente maior que $22^{\circ} \mathrm{C}$ (Vianello \& Alves, 2000) (Tabela 1). Na área experimental, de $1.800 \mathrm{~m}^{2}$, o capim-braquiária (Brachiaria decumbens) estava estabelecido há mais de oito anos e estava em processo de degradação. A área foi dividida em parcelas experimentais medindo $5 \mathrm{~m} \times 8 \mathrm{~m}$.

O solo da área é classificado como Neossolo Quartzarênico, com baixo teor de matéria orgânica. As características químicas da terra (camada superficial de 0-20 cm) na área experimental antes da aplicação dos adubos e corretivos foram: $\mathrm{pH}\left(\mathrm{CaCl}_{2}\right)=4,08$; matéria orgânica $=9,76 \mathrm{mg} / \mathrm{dm}^{3}$; fósforo $=5,34 \mathrm{mg} / \mathrm{dm}^{3}$; potássio $=$ $1,75 \mathrm{mmol}_{\mathrm{c}} / \mathrm{dm}^{3}$; cálcio $=4,00 \mathrm{mmol}_{\mathrm{c}} / \mathrm{dm}^{3} ;$ magnésio $=$ $2,30 \mathrm{mmol}_{\mathrm{c}} / \mathrm{dm}^{3}$; alumínio $=4,00 \mathrm{mmol}_{\mathrm{c}} / \mathrm{dm}^{3} ; \mathrm{H}+\mathrm{Al}=$

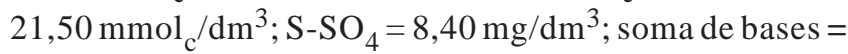
$8,05 \mathrm{mmol}_{\mathrm{c}} / \mathrm{dm}^{3}$; capacidade de troca catiônica = $29,50 \mathrm{mmol}_{\mathrm{c}} / \mathrm{dm}^{3}$; saturação por bases $=26,80 \%$. Antecedendo a aplicação dos fertilizantes, foi corrigida a acidez do solo com aplicação de calcário dolomítico (em superfície, manualmente e a lanço) de $600 \mathrm{~kg} / \mathrm{ha}$, no dia 20 de outubro de 2005, empregando-se o valor de $40 \%$ para o $\mathrm{V}_{2}$ da fórmula de cálculo da necessidade de calagem, após rebaixamento das plantas à altura de $10 \mathrm{~cm}$ da superfície do solo.

Foram estudadas combinações de cinco doses de nitrogênio ( $0 ; 150 ; 300 ; 450$ e 600 kg/ha/ano) com cinco doses de enxofre $(0 ; 15 ; 30 ; 45$ e $60 \mathrm{~kg} / \mathrm{ha} / \mathrm{ano})$, empregando-se um estudo de superfície de resposta baseado em desenho experimental composto central modificado de um fatorial $5 \times 5$ fracionado, de acordo com Littell \& Mott (1975). O delineamento experimental foi de blocos ao acaso, com três repetições. As fertilizações nitrogenada e sulfatada foram parceladas em três vezes, durante o período das águas (nas datas de 17/11/2005, 23/12/2005 e 28/01/2006). A fonte de nitrogênio foi nitrato de amônio e a de enxofre, gesso agrícola. As adubações com fósforo e potássio foram baseadas na análise química da terra e realizadas à base de $\mathrm{P}_{2} \mathrm{O}_{5}$ de $28 \mathrm{~kg} / \mathrm{ha} / \mathrm{ano}$, como superfosfato triplo,

Tabela 1 - Médias mensais de temperatura e precipitação pluvial total mensal durante o período experimental

\begin{tabular}{|c|c|c|c|c|}
\hline Mês/ano & Temperatura média diária $\left({ }^{\circ} \mathrm{C}\right)$ & Temperatura máxima $\left({ }^{\circ} \mathrm{C}\right)$ & Temperatura mínima $\left({ }^{\circ} \mathrm{C}\right)$ & Precipitação pluvial (mm) \\
\hline Novembro 2005 & 22,4 & 29,1 & 17,0 & 116,8 \\
\hline Dezembro 2005 & 22,8 & 29,2 & 17,9 & 122,4 \\
\hline Janeiro 2006 & 24,4 & 30,8 & 19,6 & 225,2 \\
\hline Fevereiro 2006 & 23,8 & 29,8 & 19,7 & 164,8 \\
\hline Março 2006 & 23,8 & 30,4 & 19,3 & 151,5 \\
\hline Abril 2006 & 21,2 & 27,9 & 15,9 & 31,7 \\
\hline Maio 2006 & 17,5 & 24,9 & 10,8 & 0,1 \\
\hline Junho 2006 & 17,5 & 25,7 & 10,4 & 18,6 \\
\hline Julho 2006 & 18,2 & 26,4 & 10,8 & 28,1 \\
\hline Agosto 2006 & 20,0 & 28,6 & 12,0 & 9,4 \\
\hline Setembro 2006 & 20,2 & 27,6 & 13,7 & 60,3 \\
\hline Outubro 2006 & 22,5 & 29,1 & 17,1 & 74,9 \\
\hline Novembro 2006 & 22,8 & 29,8 & 17,6 & 195,3 \\
\hline
\end{tabular}


e de $\mathrm{K}_{2} \mathrm{O}$ de $30 \mathrm{~kg} / \mathrm{ha} / \mathrm{ano}$, como cloreto de potássio. Para o fornecimento de micronutrientes, foi utilizada formulação FTE Br-12, com aplicação de $30 \mathrm{~kg} / \mathrm{ha}$, conforme recomendação de Monteiro et al. (2004).

As avaliações no experimento foram realizadas em intervalos predeterminados de 35 dias no período das águas e de 56 dias no período das secas, durante um ano (Tabela 2), e a área experimental foi pastejada por novilhas mestiças, durante o período de 24 horas por bloco, no intuito de rebaixar o capim-braquiária à altura de $10 \mathrm{~cm}$, altura apontada como ideal para pastejo desse capim (Machado \& Kichel, 2004). Os cortes das plantas foram realizados em área delimitada por um retângulo de madeira de $1,00 \mathrm{~m} \times 0,25 \mathrm{~m}\left(0,25 \mathrm{~m}^{2}\right)$, simulando a altura ideal de pastejo para o capim-braquiária. O quadro amostrador para coleta da parte aérea foi jogado uma vez dentro de cada parcela (uma amostra de cada parcela), de forma a coletar amostras homogêneas.

As amostras coletadas foram acondicionadas em sacos de papel, devidamente identificadas, e secas em estufa a $65^{\circ} \mathrm{C}$ por 72 horas. Posteriormente foram processadas em macromoinho tipo Wiley e acondicionadas em sacos plásticos devidamente identificados, para as determinações bromatológicas. Nessas amostras da parte aérea total, foram determinados os teores de massa seca (MS), fibra em detergente neutro (FDN), fibra em detergente ácido (FDA), digestibilidade in vitro da massa seca (DIVMS) e proteína bruta (PB).

A determinação de massa seca (MS) foi realizada conforme metodologia de Campos et al. (2004), a $105^{\circ} \mathrm{C}$, para correção dos teores de PB, FDN e FDA e da DIVMS na MS.

Nas determinações de fibra em detergente neutro e fibra em detergente ácido, utilizou-se o aparelho Ankon (Ankon 200 Fiber Analyser da Ankon Technology Corporation), segundo metodologia de Goering \& Van Soest (1970) adaptada por Campos et al. (2004). Na determinação da FDN, foi adicionado sulfito de sódio, com o objetivo de solubilizar a proteína aderida à parede celular(Van Soest, 1994) .

Tabela 2 - Ordem, data de início e de término e período das avaliações no campo

\begin{tabular}{cccc}
\hline Avaliação & Início & Término & Período \\
\hline 1 & $21 / 12 / 2005$ & $23 / 12 / 2005$ & Chuvoso \\
2 & $25 / 1 / 2006$ & $28 / 1 / 2006$ & Chuvoso \\
3 & $1 / 3 / 2006$ & $4 / 3 / 2006$ & Chuvoso \\
4 & $5 / 4 / 2006$ & $8 / 4 / 2006$ & Chuvoso \\
5 & $10 / 5 / 2006$ & $13 / 5 / 2006$ & Chuvoso \\
6 & $5 / 7 / 2006$ & $8 / 7 / 2006$ & Seco \\
7 & $30 / 8 / 2006$ & $2 / 9 / 2006$ & Seco \\
8 & $25 / 10 / 2006$ & $28 / 10 / 2006$ & Seco \\
\hline
\end{tabular}

Para avaliação da digestibilidade in vitro da massa seca, seguiu-se a metodologia de Tilley \& Terry (1963), adaptada por Campos et al. (2004). Os animais utilizados para a retirada do conteúdo de líquido de ruminal (inóculo) estavam submetidos a dietas exclusivas de feno de capimelefante (Pennisetum purpureum).

A determinação do nitrogênio total nas amostras foi efetuada segundo o método semimicro Kjeldhal, conforme a metodologia descrita por Sarruge \& Haag (1974), para posterior estimativa da concentração de proteína bruta (PB), usando fator 6,25 para conversão de nitrogênio em proteína bruta (AOAC, 1970).

Todos os resultados foram submetidos às análises estatísticas utilizando-se o aplicativo SAS (2000). Utilizou-se inicialmente o teste $\mathrm{F}$ e, para casos de significância $(\mathrm{P}<0,05)$ da interação nitrogênio $\times$ enxofre, efetuaram-se análises de regressão polinomial (superfície de resposta) pelo procedimento RSREG. Nos casos de interação nãosignificativa $(\mathrm{P}>0,05)$, utilizou-se o procedimento GLM para os estudos de regressão.

\section{Resultados e Discussão}

Para a concentração de proteína bruta (PB) na massa seca do capim-braquiária a interação nitrogênio $\times$ enxofre no período chuvoso não foi significativa na recuperação da pastagem. Na primeira, segunda e quinta avaliações do período chuvoso, a análise de variância revelou significância para as doses de nitrogênio, com ajuste dos resultados ao modelo linear de regressão, corroborando assim o relato da maioria dos trabalhos encontrados na literatura. As concentrações de PB aumentaram conforme as doses de nitrogênio, variando de 14,4 a $18,8 \%$ na primeira avaliação (Figura 1A), de 6,2 a 14,7\% na segunda avaliação (Figura 1B) e de 7,4 a 11,9\% na quinta avaliação (Figura 1C). A média das concentrações de PB na primeira avaliação foi superior à das outras duas avaliações, pois, em parcelas não-adubadas com nitrogênio e enxofre, na primeira avaliação, não houve material suficiente para a determinação dos teores de PB.

O valor nutritivo da forragem (entre os quais está a proteína bruta) pode ser alterado pelo ambiente (temperatura, água, fertilidade do solo, entre outros). Scheffer-Basso \& Gallo (2008) observaram que as características relacionadas ao valor nutritivo do capimcoqueirinho tiveram maior alteração dos 27 aos 68 dias de idade e, a partir daí, tenderam à estabilização. Esse comportamento decorreu de seu crescimento mais lento durante as estações menos favoráveis, ao contrário do que ocorre em temperaturas mais altas. 

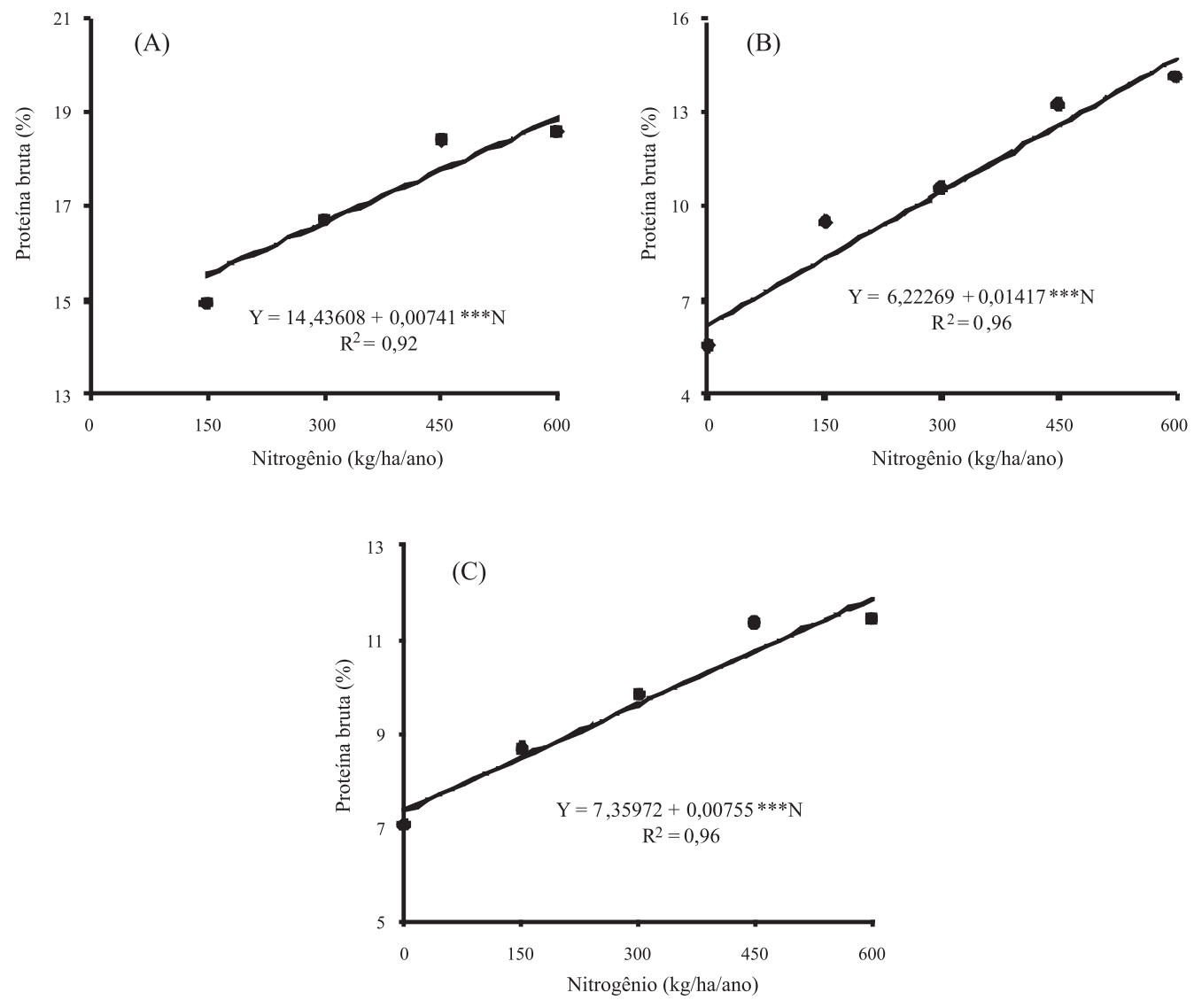

Figura 1 - Concentração de proteína bruta na massa seca do capim-braquiária nas amostras da primeira (A), segunda (B) e quinta (C) avaliações do período chuvoso mediante adubação nitrogenada.

*** Significativo a $0,1 \%$.

É possível também que, no decorrer do primeiro período de crescimento após a adubação, a gramínea forrageira tenha acumulado mais nutrientes (no caso o nitrogênio) para compensar longos períodos de deficiência nutricional, decorrente da baixa disponibilidade do nutriente no solo.

Moreira et al. (2009), estudando a influência do nitrogênio aplicado todos os meses durante dois anos na parte aérea do capim-braquiária, verificaram que as doses de nitrogênio promoveram aumento linear nas concentrações de PB nas folhas, confirmando o observado por Andrade et al. (1996), que demonstraram adubação nitrogenada aumentando a concentração de proteína bruta do capim-marandu (Brachiaria brizantha).

Na terceira e quarta avaliações do período chuvoso, observaram-se efeitos significativos das doses de nitrogênio na concentração de $\mathrm{PB}$, cujos resultados ajustaram-se ao modelo quadrático de regressão. As mais altas concentrações de proteína bruta (19,0 e 11,8\%) foram observadas nas doses de nitrogênio de 550 e 424 kg/ha/ano, respectivamente, na terceira (Figura 2A) e quarta (Figura 2B) avaliações do período chuvoso.
Rodrigues (2002), estudando a recuperação da Brachiaria decumbens com aplicação de calcário, nitrogênio e enxofre, observou efeito significativo do nitrogênio na concentração de PB nas folhas, cujos resultados ajustaram-se ao modelo quadrático de regressão. Poucos trabalhos encontrados na literatura indicam respostas quadráticas de variação da concentração de PB com o aumento das doses de nitrogênio, pois, na maioria dos casos, as respostas ajustaram-se ao modelo linear de regressão, em decorrência possivelmente do fato de que, na maioria dos trabalhos, foram utilizadas doses anuais inferiores a $450 \mathrm{~kg} / \mathrm{ha} / \mathrm{ano}$.

No período chuvoso, as concentrações de PB nas três primeiras avaliações apresentaram limites superiores aos das duas últimas avaliações desse período, o que pode ser explicado pela proximidade de tempo entre as adubações e essas avaliações.

No período seco do primeiro ano de recuperação do capim-braquiária, somente na primeira avaliação, a interação doses de nitrogênio $\times$ enxofre foi significativa para a concentração de PB (Figura 3); os resultados ajustaram-se ao modelo polinomial de regressão. De acordo 

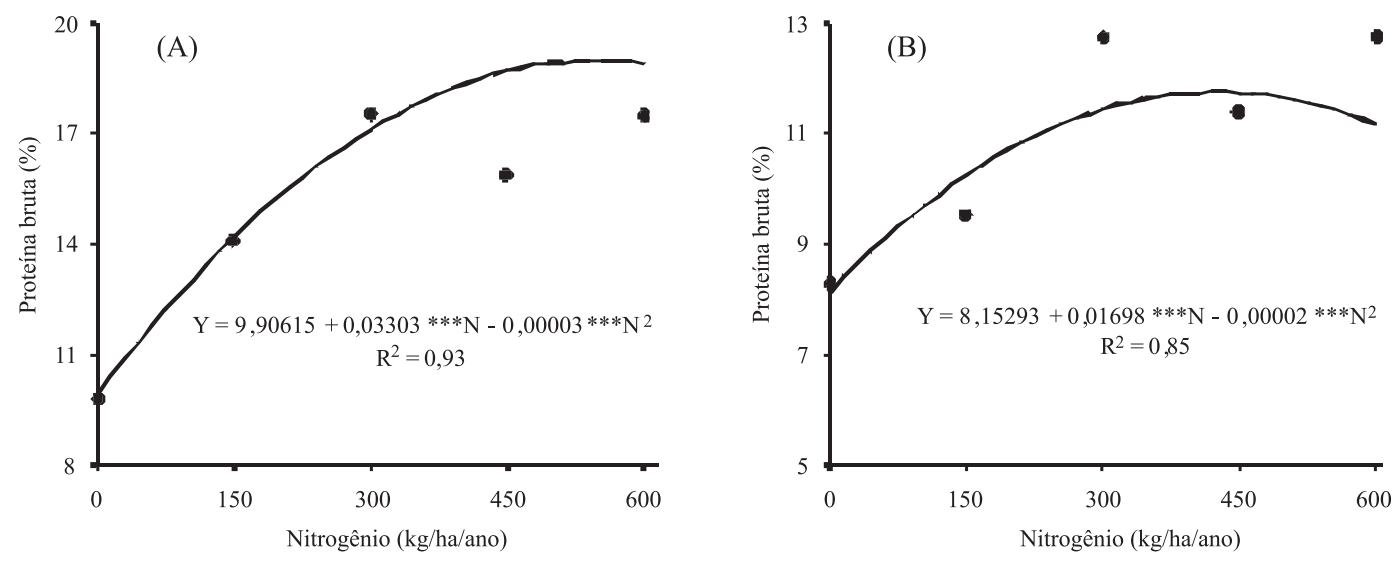

Figura 2 - Concentração de proteína bruta (PB) na massa seca do capim-braquiária na terceira (A) e quarta (B) avaliações do período chuvoso mediante adubação nitrogenada.

*** Significativo a $0,1 \%$.

com a superfície de resposta, houve aumento na concentração de PB conforme aumentaram as doses de nitrogênio. Além disso, observou-se que as concentrações mais altas de PB foram encontradas nas mais altas doses de nitrogênio e nas mais baixas doses de enxofre. Esse aumento na concentração de proteína bruta com o fornecimento de nitrogênio é documentado na literatura. Além disso, o nitrogênio contribuiu para maior proporção de folhas nas plantas, assim como apontado por Lemaire \& Chapmam (1996), e as folhas normalmente possuem maior concentração de nitrogênio.

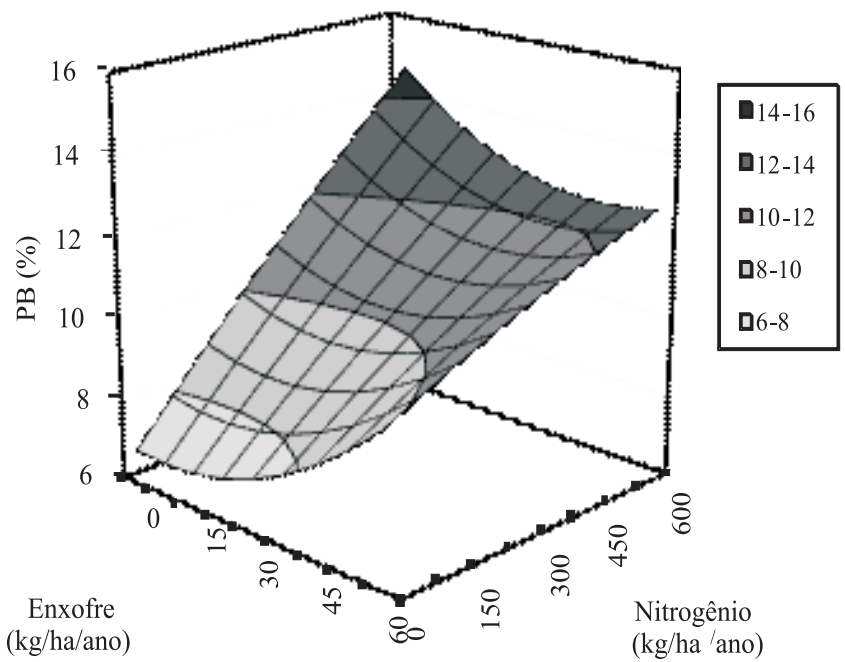

$\mathrm{Y}=6,849908+0,014215 * * * N-0,000002071 * * * N^{2}-0,014519 * S+0,001043^{*} \mathrm{~S}^{2}-0,000138 * * \mathrm{NS}$ $\mathbf{R}^{2}=\mathbf{0 , 8 4}$

Figura 3 - Concentração de proteína bruta (PB) na massa seca do capim-braquiária, na primeira avaliação do período seco mediante adubação com nitrogênio e enxofre.

***; ** e * Significativo a 0,$1 ; 1$ e $5 \%$, respectivamente.
Cunha et al. (2001) aplicaram doses de nitrogênio e de enxofre para a produção e o valor nutritivo da forragem de campo natural de Planossolo no Rio Grande do Sul e verificaram, no primeiro corte das plantas, significativo efeito do nitrogênio e do enxofre na concentração de PB. No segundo corte, constataram significância para a interação nitrogênio $\times$ enxofre, com ajuste dos resultados ao modelo polinomial de regressão.

Na segunda e terceira avaliações do período seco, observou-se efeito significativo das doses de nitrogênio na concentração de PB. Na segunda avaliação, os resultados ajustaram-se ao modelo quadrático de regressão, e a máxima concentração de proteína bruta (13,9\%) foi observada na dose de nitrogênio de 565 kg/ha/ano (Figuras 4A). Na terceira avaliação, a análise de regressão mostrou ajuste dos resultados ao modelo linear de regressão (Figura 4B), de modo que as concentrações de PB aumentaram conforme as doses de nitrogênio, com variação de 11,7 a 17,2\%.

Respostas significativas da concentração de PB de gramíneas tropicais à aplicação de nitrogênio, com ajuste ao modelo linear de regressão, também foram observadas por Andrade et al. (1996) e Quadros \& Rodrigues (2006).

É importante salientar que as concentrações médias de proteína bruta no capim adubado em cada uma das oito avaliações, tanto no período chuvoso quanto no seco, foi superior a 7\%, nível crítico para o atendimento das necessidades nutricionais dos ruminantes, conforme Minson \& Wilson (1994). Em alguns casos da não-aplicação da adubação com nitrogênio e enxofre, as concentrações de PB foram inferiores a esse valor considerado crítico, como ocorreu nas segunda e quinta avaliações do período chuvoso.

As variáveis de degradação e a taxa de passagem ruminal baseiam-se na FDN da forrageira (Madsen et al., 1997). De 

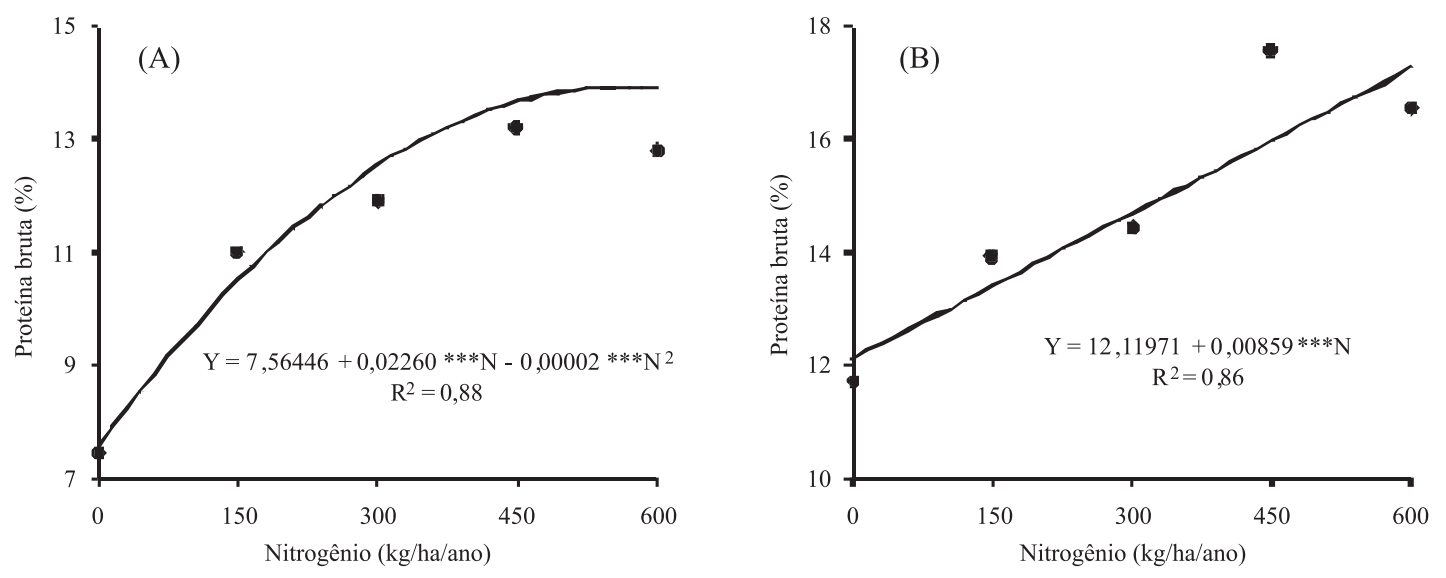

Figura 4 - Concentração de proteína bruta (PB) na massa seca do capim-braquiária na segunda (A) e terceira (B) avaliações do período seco mediante adubação nitrogenada. *** Significativo a $0,1 \%$.

acordo com Lima et al. (2002), a FDN apresenta relação inversamente proporcional à densidade energética da dieta, e valores de FDN acima de 60\% correlacionam-se negativamente com consumo de forragem (Mertens, 1996).

Para o teor de FDN (que inclui hemicelulose, celulose e lignina) na massa seca do capim-braquiária no período chuvoso, a interação nitrogênio $\times$ enxofre não foi significativa. Com exceção da primeira avaliação, quando não houve resposta significativa à aplicação de nitrogênio e enxofre, nas quatro demais avaliações do período chuvoso, a variação no teor de FDN foi significativa para as doses de nitrogênio.

Na segunda e terceira avaliações do período chuvoso, o teor de FDN variou com as doses de nitrogênio segundo modelo quadrático de regressão e foram verificados teores mínimos de FDN de 71,0 e 67,0\%, nas doses de nitrogênio de 428 e 468 kg/ha/ano, respectivamente para a segunda (Figura 5A) e terceira (Figura 5B) avaliações.

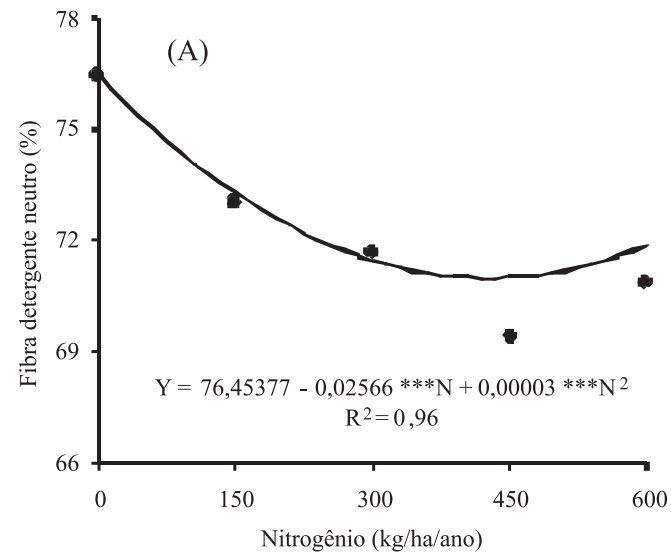

A adubação nitrogenada ocasiona mudanças estruturais e na composição química dos tecidos da planta. Consequentemente, a elevação dos constituintes estruturais, como fibras e lignina, pode ter acarretado decréscimo na concentração de PB.

Na quarta avaliação do período chuvoso, não houve resposta significativa do teor de FDN para as doses de nitrogênio e enxofre e o valor médio encontrado foi de 72,7\%.

Na quinta avaliação do período chuvoso, a análise de variância revelou significância para as doses de nitrogênio, com ajuste dos resultados ao modelo linear de regressão (Figura 6). Conforme aumentaram as doses de nitrogênio, os teores de FDN foram diminuindo, com variação de 71,6 a 68,8\%.

Costa et al. (2009), avaliando doses de nitrogênio na composição bromatológica do capim-marandu em estágio moderado de degradação, observaram redução nos teores de FDN com o aumento das doses de nitrogênio, de modo

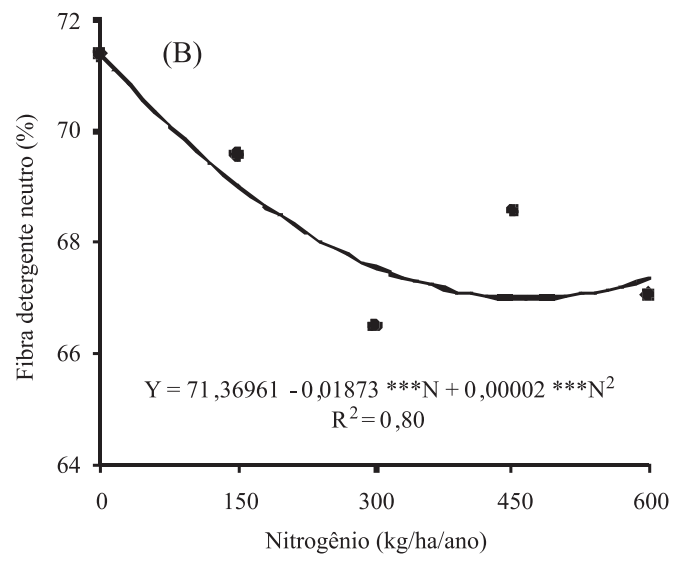

Figura 5 - Teor de fibra em detergente neutro (FDN) na massa seca do capim-braquiária nas amostras da segunda (A) e terceira (B) avaliações do período chuvoso mediante adubação com nitrogênio. 
que os resultados ajustaram-se ao modelo linear de regressão. O menor teor foi obtido na dose de nitrogênio de 300 kg/ha, com redução de 8,93\% em relação a não-aplicação de nitrogênio.

No período seco do primeiro ano de recuperação do capim-braquiária, a interação nitrogênio $\times$ enxofre foi significativa para o teor de fibra em detergente neutro (FDN) somente na primeira avaliação, com o ajuste dos resultados ao modelo polinomial de regressão (Figura 7). De acordo com a superfície de resposta, o teor de FDN diminuiu nas doses mais elevadas de nitrogênio e os teores mais elevados de FDN (em torno de 75\%) foram obtidos na combinação de baixas doses de nitrogênio e enxofre.

Na segunda avaliação do período seco, observou-se efeito significativo das doses de nitrogênio no teor de FDN e os resultados ajustaram-se a uma função inversa (Figura 8A), que comprovou comportamento decrescente do teor de FDN em comparação à não-aplicação de nitrogênio com a dose de 150 kg/ha/ano. Houve abrupta diminuição nos teores de FDN com esse aumento das doses de nitrogênio, até que esses teores se mantiveram constantes com aumento no fornecimento de nitrogênio. Essa resposta indica que a aplicação de nitrogênio de 0 a 150 kg/ha/ano influencia os teores de FDN, porém, a partir desse ponto, o aumento das doses de nitrogênio não mais proporciona variação dos teores de FDN no capim-braquiária em recuperação. O teor médio encontrado foi de 65,25\%.

Na terceira avaliação do período seco, a análise de variância revelou significância para as doses de nitrogênio no teor de FDN, com ajuste dos resultados ao modelo linear

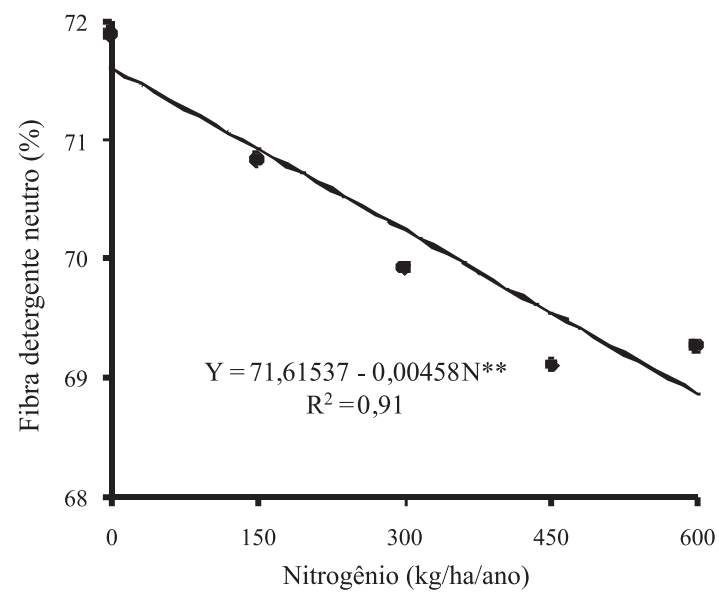

Figura 6 - Teor de fibra em detergente neutro (FDN) na massa seca do capim-braquiária na quinta avaliação do período chuvoso mediante adubação nitrogenada.

** Significativo a $1 \%$.

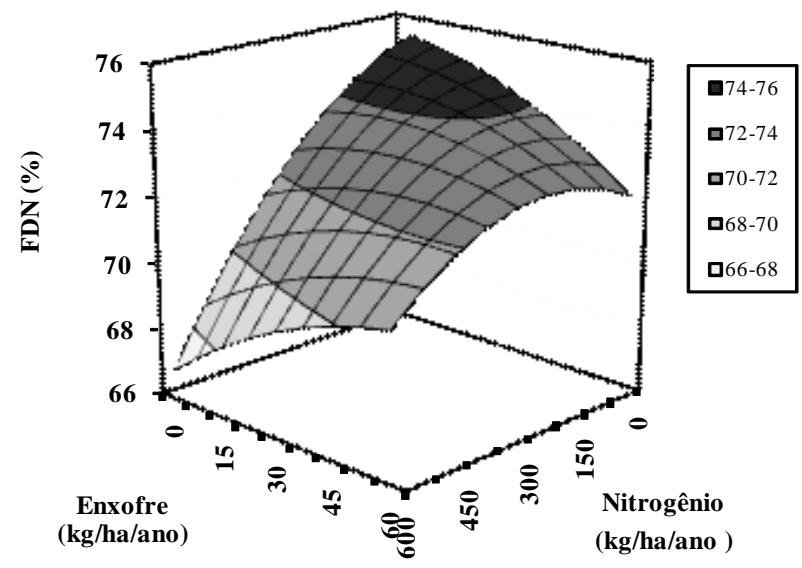

$\mathrm{Y}=75,413007-0,004363^{* * *} \mathrm{~N}-0,000016446 * * * \mathrm{~N}^{2}-0,019333^{*} \mathrm{~S}-0,000643^{*} \mathrm{~S}^{2}+0,000194 * * * \mathrm{NS}$ $\mathbf{R}^{2}=\mathbf{0 , 7 0}$

Figura 7 - Teor de fibra em detergente neutro (FDN) na massa seca do capim-braquiária na primeira avaliação do período seco mediante adubação com nitrogênio e enxofre.

*** e * Significativo a 0,1 e $5 \%$.

de regressão (Figura 8B). Conforme aumentaram as doses de nitrogênio ( 0 a 600 kg/ha/ano), os teores de FDN foram diminuindo (de 63,2 a 59,5\%).

No primeiro ano de recuperação do capim-braquiária, para o teor de fibra em detergente ácido (FDA), que inclui celulose e lignina, na massa seca do capim, a interação nitrogênio $\times$ enxofre não foi significativa nas avaliações do período chuvoso.

Os teores de FDA na segunda e quarta avaliações do período de chuvas ajustaram-se ao modelo linear de regressão e essas respostas foram diferenciadas. No modelo linear da segunda avaliação, conforme aumentaram as doses de nitrogênio, os teores de FDA foram diminuindo e variaram de 45,0 a 39,5\% (Figura 9A). Esse decréscimo é considerado importante, pois o teor de FDA indica a digestibilidade de um alimento. À medida que há aumento dos teores de FDA da forrageira, com aumento nos teores de componentes lignificados, diminui a digestibilidade da massa seca, comprometendo o aproveitamento da forragem ingerida.

$\mathrm{Na}$ quarta avaliação do período chuvoso, os teores de FDA aumentaram conforme as doses de nitrogênio, e a variação foi de 41,1 a 44,8\% (Figura 9B). A possível causa desse acréscimo pode ter sido o aumento de tecidos lignificados nas plantas durante esse período. A elevação dos teores de FDA com a adubação nitrogenada não é comum. Burton (1998) explicou que as adubações, principalmente a nitrogenada, além de elevar a produção de 

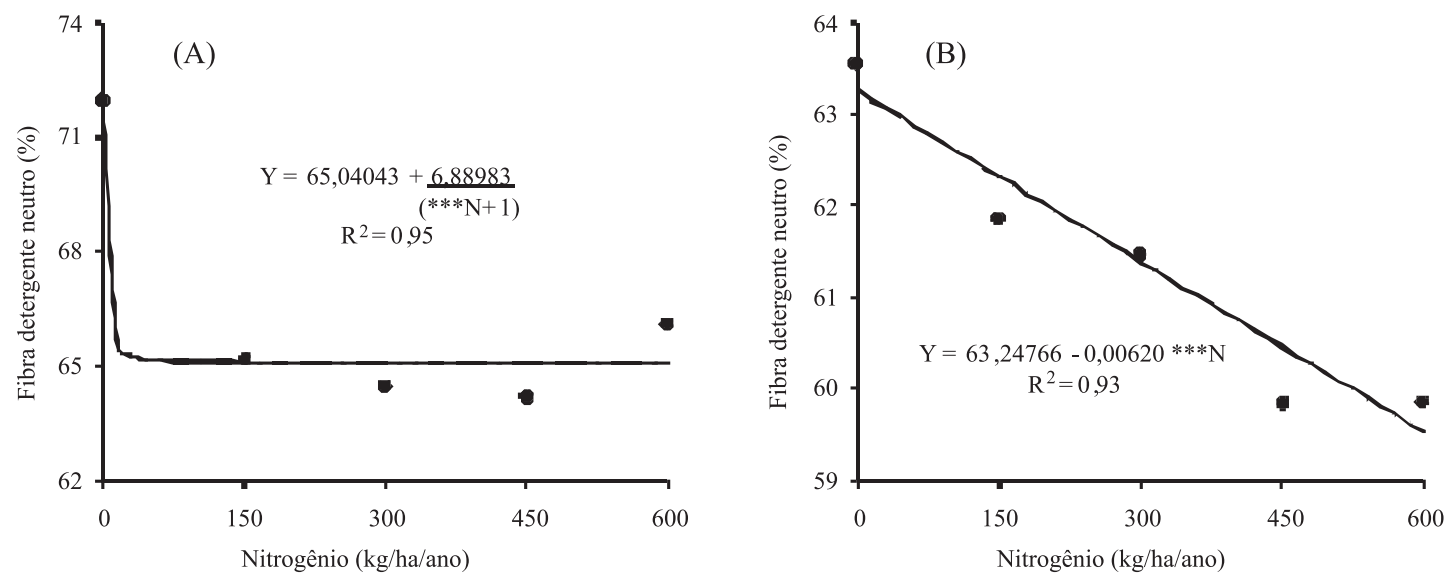

Figura 8 - Teor de fibra em detergente neutro (FDN) na massa seca do capim-braquiária na segunda (A) e terceira (B) avaliações do período seco mediante adubação nitrogênio.

*** Significativo a $0,1 \%$.

massa seca, aumentam a concentração de proteína bruta da forragem e, em alguns casos, diminuem o teor de fibra, contribuindo para a melhoria da sua qualidade.

O aumento no teor de FDA na quarta avaliação com o aumento das doses de nitrogênio pode ser justificado pelas condições ambientais a que as plantas foram expostas durante o período experimental e pela maior produção de massa seca da planta forrageira com a aplicação das doses de nitrogênio.

Costa et al. (2006), avaliando efeitos qualitativos e quantitativos do nitrogênio e do potássio no desenvolvimento Brachiaria brizantha cv. MG-5, observaram efeito significativo da aplicação de nitrogênio no teor de FDA, que ficou em torno de 30,2\% para as maiores doses de nitrogênio aplicadas (200 kg/ha), comprovando redução de 4,2\% em comparação à testemunha.

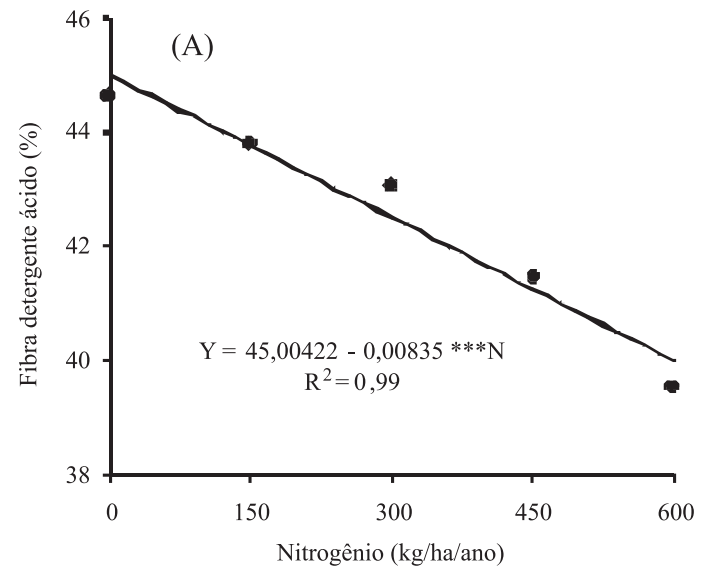

No período seco do primeiro ano de recuperação do capim-braquiária, a interação nitrogênio $\times$ enxofre foi significativa para teor de FDA na massa seca do capim somente na primeira avaliação, com o ajuste dos resultados ao modelo polinomial de regressão (Figura 10A). De acordo com a superfície de resposta, o teor de FDA aumentou conforme as doses de nitrogênio, até atingir o teor máximo de FDA (45\%), na combinação de nitrogênio e de enxofre de 243 e 27 kg/ha/ano, respectivamente. Em doses mais elevadas de ambos os nutrientes, constatou-se decréscimo dos teores de FDA.

O teor de FDA na parte aérea do capim-braquiária na segunda avaliação do período seco do ano foi influenciado significância para as doses de nitrogênio, de modo que os resultados ajustaram-se ao modelo linear de regressão. À medida que as doses de nitrogênio aumentaram, os teores

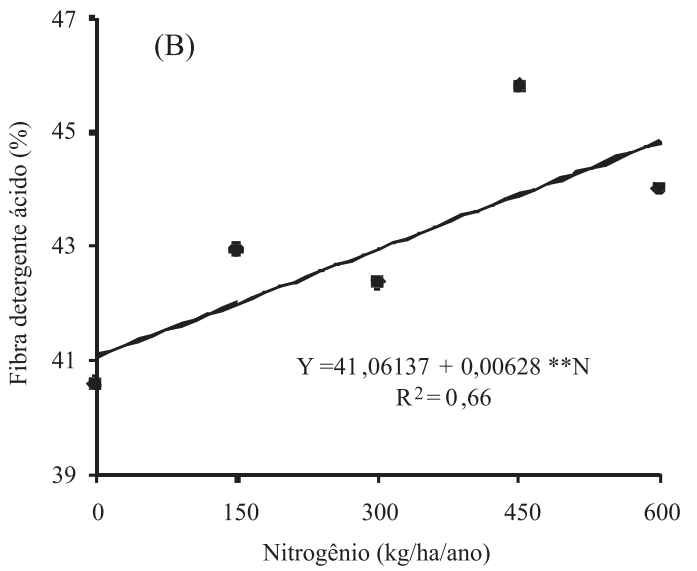

Figura 9 - Teor de fibra em detergente ácido (FDA) na massa seca do capim-braquiária nas amostras da segunda (A) e quarta (B) avaliações do período chuvoso mediante adubação nitrogenada.

*** e ** Significativo a 0,1 e $1 \%$. 
de FDA diminuíram e mantiveram-se entre 34,7 e 39,7\% (Figura 10B). Na terceira avaliação, não houve variação significativa no teor de FDA com as doses de nitrogênio ou de enxofre.

Nas avaliações do período chuvoso do primeiro ano de recuperação do capim-braquiária, a interação nitrogênio $x$ enxofre não foi significativa para a digestibilidade in vitro da massa seca do capim. Na primeira avaliação desse período, a DIVMS não sofreu influência significativa, nem das doses de nitrogênio nem das doses de enxofre, enquanto, na segunda, terceira e quinta avaliações, a DIVMS variou significativamente com as doses de nitrogênio, e os os resultados ajustaram-se ao modelo linear de regressão. À medida que aumentaram as doses de nitrogênio, a DIVMS elevou de 53,8 para 66,7\% na segunda avaliação (Figura 11A), de 63,0 para 72,0\% na terceira avaliação (Figura 11B) e de 56,3 para 60,2\% na quinta avaliação (Figura 11D).

Na quarta avaliação do período chuvoso, a DIVMS respondeu de forma significativa às doses de enxofre, com ajuste dos resultados ao modelo quadrático de regressão. O valor mínimo de DIVMS encontrado foi de $61 \%$ e foi atingido na dose de enxofre de $28 \mathrm{~kg} / \mathrm{ha} / \mathrm{ano}$ (Figura 11C). A diminuição da digestibilidade pode ter sido favorecida pelo aumento dos teores de FDA. Possivelmente ocorreu aumento nos teores de componentes lignificados.

Euclides et al. (2007), avaliando as características do pasto de capim-tanzânia (Panicum maximum) adubado com nitrogênio no final do verão, verificaram aumentos na digestibilidade in vitro apenas em março, logo após a adubação nitrogenada.

Quadros \& Rodrigues (2006), estudando o valor nutritivo dos capins Panicum maximum cv. Tanzânia e

(A)

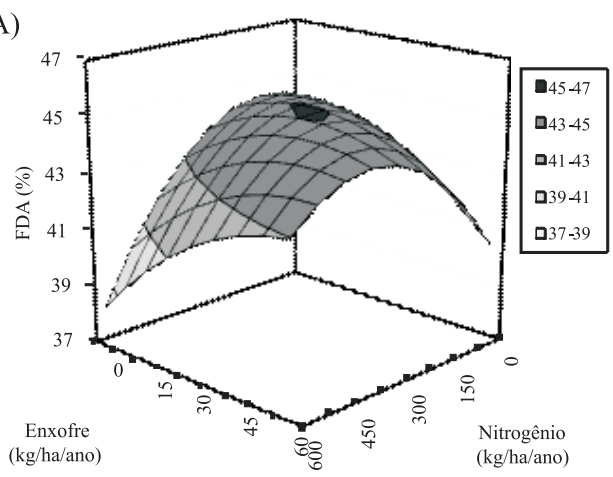

$\mathrm{Y}=44,094945+0,007661 * \mathrm{~N}-0,000028+\mathrm{N} 2 \div 0,002720 * \mathrm{~S}-0,001082 * \mathrm{~S} 2+0,000230 * \mathrm{NS}$ $\mathrm{R}^{2}=0,65$ cv. Mombaça adubados com nitrogênio e sob lotação rotacionada, encontraram aumento linear na DIVMS com o aumento das doses de nitrogênio.

Ruggieri et al. (1995) estudaram a influência de doses de nitrogênio e regimes de corte na distribuição na composição bromatológica e na digestibilidade in vitro da massa seca do capim-marandu e verificaram aumento na DIVMS das folhas com o aumento das doses de nitrogênio, independentemente das idades de corte.

Nas avaliações do período seco, a interação nitrogênio $\times$ enxofre não influenciou a DIVMS do capim, mas isoladamente as doses de nitrogênio na primeira e segunda avaliações afetaram essa variável, enquanto, na terceira avaliação, não ocasionou variações.

Na primeira avaliação da época seca do ano, os resultados ajustaram-se ao modelo quadrático de regressão. O valor mínimo encontrado foi de $51 \%$ e foi atingido na dose de nitrogênio de DIVMS de $118 \mathrm{~kg} / \mathrm{ha} / \mathrm{ano}$ (Figura 12A). Na segunda avaliação do período seco, a regressão mostrou ajuste dos resultados ao modelo linear (Figura 12B) e, conforme aumentaram as doses de nitrogênio, a DIVMS elevou de 57,7 para 69,0\%.

Resultados encontrados na literatura têm sido inconsistentes quanto aos efeitos da adubação nitrogenada na digestibilidade de gramíneas forrageiras. Cecato et al. (2004), estudando a influência das adubações nitrogenada e fosfatada sobre a composição química do capim-marandu, verificaram que a DIVMS das plantas não foi influenciada pelos níveis de nitrogênio. Esse resultado está de acordo com aqueles citados por Gomide \& Queiroz (1994) para Brachiaria decumbens. No entanto, Ruggieri et al. (1995) observaram aumento na DIVMS nas folhas do capim-marandu de acordo com a dose de adubo nitrogenado.

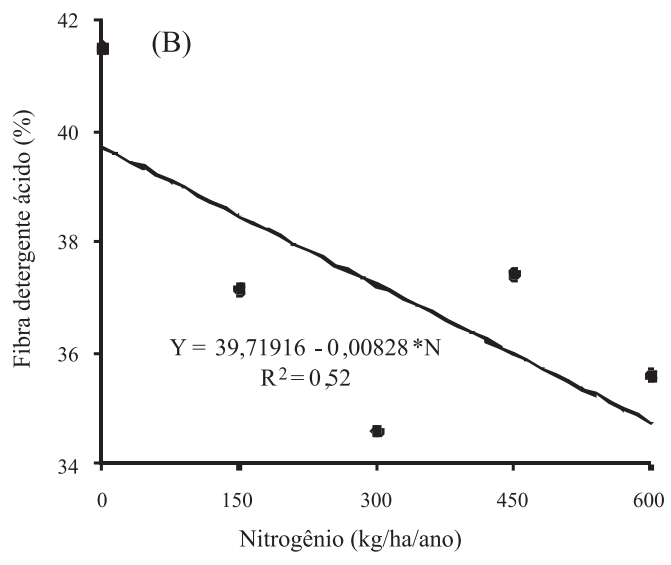

Figura 10 - Teor de fibra em detergente ácido (FDA) na massa seca do capim-braquiária na primeira avaliação do período seco, mediante * Significativo a $5 \%$ a adubação com nitrogênio e enxofre (A), e na segunda (B) avaliação, mediante adubação com nitrogênio. 

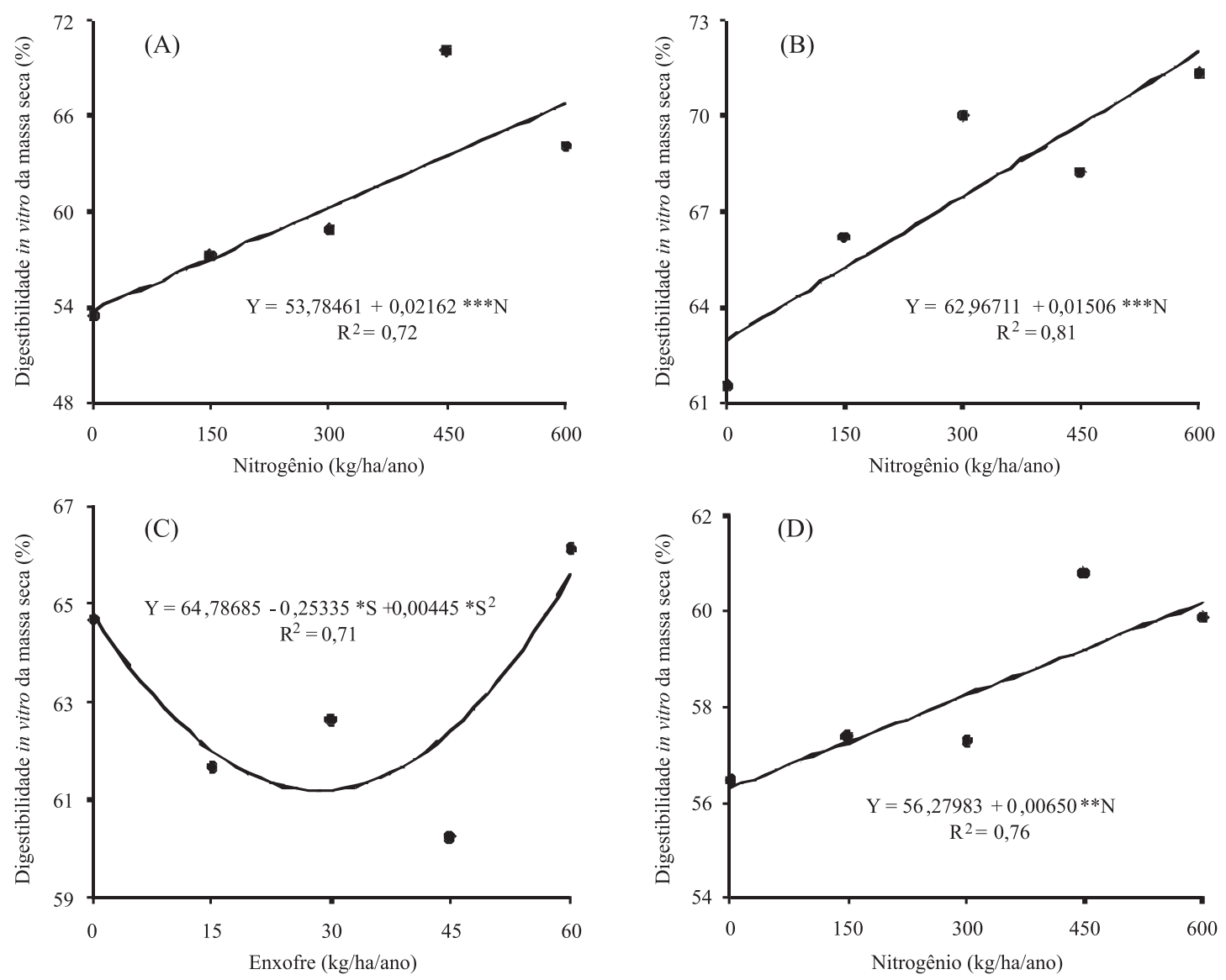

Figura 11 - Digestibilidade in vitro da massa seca (DIVMS) do capim-braquiária no período chuvoso nas amostras da segunda (A), terceira (B) e quinta (D) avaliações, mediante adubação com nitrogênio, e na quarta avaliação (C), mediante adubação com enxofre.

***; ** e * Significativo a 0,$1 ; 1$ e $5 \%$, respectivamente.
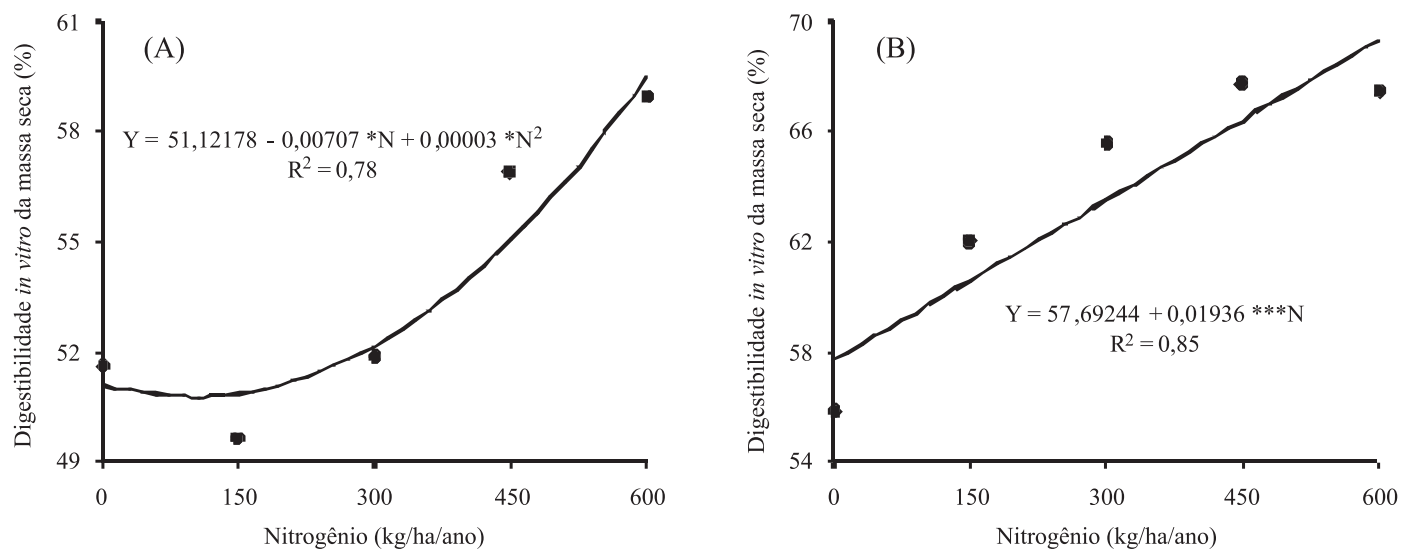

Figura 12 - Digestibilidade in vitro da massa seca (DIVMS) do capim-braquiária nas amostras da primeira (A) e segunda (B) avaliações do período seco mediante adubação com nitrogênio.

*** e * Significativo a 0,1 e $5 \%$.

\section{Conclusões}

A combinação de doses de nitrogênio e de enxofre altera a concentração de proteína bruta e fibra em detergente neutro e de fibra em detergente ácido na primeira avaliação do período seco. Doses de nitrogênio de até $600 \mathrm{~kg} / \mathrm{ha} / \mathrm{ano}$ promovem variação linear e quadrática na concentração de proteína bruta e nos teores de fibra em detergente neutro e 
de fibra em detergente ácido e na digestibilidade in vitro da massa seca. Doses de enxofre de até $60 \mathrm{~kg} / \mathrm{ha} / \mathrm{ano}$ influenciam a digestibilidade in vitro da massa seca somente no período chuvoso.

\section{Referências}

ANDRADE, J.B.; BENINTENDE, R.P.; FERRARI JR., E. et al. Efeito das adubações nitrogenada e potássica na produção e composição de Brachiaria ruziziensis. Pesquisa Agropecuária Brasileira, v.31, n.9, p.617-620, 1996.

ASSOCIATION OF OFFICIAL ANALYTICAL CHEMISTS - AOAC. Official methods of analyses. Washington, D.C.: AOAC, 1970. 1015p.

BODDEY, R.M.; MACEDO, R.; TARRÉ, R.M. et al. Nitrogen cycling in Brachiaria pastures: the key to understanding the process of pasture decline. Agriculture, Ecosystems and Environment, v.103, p.389-403, 2004.

BURTON, G.W. Registration of Tifton 78 Bermuda grass. Crop Science, v.28, n.2, p.187-188, 1998.

CAMPOS, F.P.; NUSSIO, C.M.B.; NUSSIO, L.G. Métodos de análises de alimentos. Piracicaba: Fundação de Estudos Agrários Luiz de Queiroz, 2004. 135p.

CECATO, U.; PEREIRA, L.A.F.; JOBIM, C.C. et al. Influência das adubações nitrogenada e fosfatada sobre a composição químicobromatológica do capim Marandu (Brachiaria brizantha (Hochst) Stapf cv. Marandu). Acta Scientiarum. Animal Sciences, v.26, n.3, p.409-416, 2004.

COSTA, K.A.P.; OLIVEIRA, I.P.; FAQUIN, V. et al. Efeitos quantitativo e qualitativa do nitrogênio e do potássio no desenvolvimento da Brachiaria brizantha cv. MG-5. Revista Eletrônica Faculdade Montes Belos, v.1, n.1, p.56-70, 2006.

COSTA, K.A.P.; OLIVEIRA, I.P.; FAQUIN, V. et al. Produção de massa seca e nutrição nitrogenada de cultivares de Brachiaria brizantha (A. Rich) Stapf sob doses de nitrogênio. Ciência e Agrotecnologia, v.33, n.6, p.1578-1585, 2009.

CUNHA, M.A.D.; LEITE, G.G.; DIOGO, J.M.S. et al. Características morfológicas do Paspalum citratum cv. Pojuca submetido ao pastejo rotacionado. Dinâmica de perfilhamento e elongação de folhas. Revista Brasileira de Zootecnia, v.30, n.3, p.935-940, 2001.

DIAS-FILHO, M.B. Degradação de pastagens. Processos, causas e estratégias de recuperação. Belém: Embrapa Amazônia Oriental, 2005. 173p.

EUCLIDES, V.P.B.; MACEDO, M.C.M.; ZIMMER, A.H. et al. Características do pasto de capim-tanzânia adubado com nitrogênio no final do verão. Pesquisa Agropecuária Brasileira, v.42, n.8, p.1189-1198, 2007.

GOMIDE, J.A.; QUEIROZ, D.S. Valor alimentício das Brachiarias. In: SIMPÓSIO SOBRE MANEJO DA PASTAGEM, 11., 1994, Piracicaba. Anais... Piracicaba: Fundação de Estudos Agrários Luiz de Queiroz, 1994. p.223.

LEMAIRE, G.; CHAPMAN, D. Tissue flows in grazed plant communities. In: HODGSON, J.; ILLIUS, A.W. (Eds.) The ecology and management of grazing systems. 1.ed. CAB INTERNATIONAL, 1996. p.3-36.

LIMA; L.G.; NUSSIO; L.G.N.; GONÇALVES, J.R.S. et al. Fontes de amido e proteína para vacas leiteiras em dietas à base de capim elefante. Scientia Agricola, v.59, n.1, p.19-27, 2002.

LITTELL, R.C.; MOTT, G.O. Computer assisted design and analysis of response surface experiments in agronomy. Soil and Crop Society of Florida Proceedings, v.34, n.1, p.94-97, 1975.
MACHADO, L.A.Z; KICHEL, A.N. Ajuste de lotação no manejo de pastagens. Dourados: Embrapa Agropecuária Oeste, 2004. 55p. (Documentos 62).

MACEDO, M.C.M. Pastagens no ecossistema Cerrados: evolução das pesquisas para o desenvolvimento sustentável. In: REUNIÃO ANUAL DA SOCIEDADE BRASILEIRA DE ZOOTECNIA, 42., 2005, Goiânia. Anais... Goiânia: SBZ/UFG, [2005]. (CD-ROM).

MADSEN, J.; HVELPLUND, T.; WEISBJERG, M.R. Appropriate methods for evaluation of tropical feeds for ruminants. Animal Feed Science and Technology, v.69, n.2, p.53-66, 1997.

MARSCHNER, H. Mineral nutrition of higher plants. London: Academic Press, 1995. 889p.

MERTENS, D.R. Using fiber and carbohydrate analyses to formulate dairy rations. Formulating dairy rations. Informational Conference with Dairy and Forage Industries, US, Dairy Forage Research Center, 1996. p.81-92.

MINSON, J.D.; WILSON, J.R. Prediction of intake as na element of forage quality. In: FAHEY JR., G.C.; COLLINS, M.; MERTENS, D.R. et al. (Eds.). Forage quality, evaluation and utilization. Madison: American Society of American, 1994. p.533-563.

MONTEIRO, F.A.; COLOZZA, M.T; WERNER, J.C. Enxofre e micronutrientes em pastagens. In: SIMPÓSIO SOBRE MANEJO DA PASTAGEM, 21., 2004, Piracicaba. Anais... Piracicaba: Fundação de Estudos Agrários Luiz de Queiroz, 2004. p.279-301.

MOREIRA, L.M.; MARTUSCELLO, J.A.; FONSECA, D.M. et al. Perfilhamento, acúmulo de forragem e composição bromatológica do capim-braquiária adubado com nitrogênio. Revista Brasileira de Zootecnia, v.38, n.9, p.1675-1684, 2009.

QUADROS, D.G.; RODRIGUES, L.R.A. Valor nutritivo dos capins Tanzânia e Mombaça adubados com nitrogênio e sob lotação rotacionada. Acta Scientiarum. Zootechny, v.28, n.4, p.385-392, 2006.

RODRIGUES, R.C. Calcário, nitrogênio e enxofre para recuperação do capim-Braquiária cultivado em solo proveniente de uma pastagem degradada. 2002. 141f. Dissertação (Mestrado em Ciência Animal e Pastagem) - Escola Superior de Agricultura "Luiz de Queiroz”/Universidade de São Paulo, Piracicaba.

RUGGIERI, A.C.; FAVORETTO, V.; MALHEIROS, E.B. Efeito de níveis de nitrogênio e regimes de corte na distribuição, na composição bromatológica e na digestibilidade "in vitro" da matéria seca da Brachiaria brizantha (Hochst) Stapf cv. marandu. Revista da Sociedade Brasileira de Zootecnia, v.24, n.1, p.20-30, 1995.

SARRUGE, J.R.; HAAG, H.P. Análises químicas em plantas. Piracicaba: Escola Superior de Agricultura "Luiz de Queiroz", 1974. 54p.

SCHEFFER-BASSO, S.M.; GALLO, M.M. Aspectos morfofisiológicos e bromatológicos de paspalum plicatulum. Revista Brasileira de Zootecnia, v.37, n.10, p.1758-1762, 2008.

SOARES FILHO, C.V.; MONTEIRO, F.A.; CORSI, M. Recuperação de pastagens degradadas de Brachiaria decumbens. 1. Efeito de diferentes tratamentos de fertilização e manejo. Pasturas Tropicales, v.14, n.2, p.1-6, 1992.

STATISTICAL ANALYSIS SYSTEM - SAS. The SAS system for Windows, Release 8.0. Cary: SAS Institute, 2000. 633p.

VAN SOEST, P.J. Nutritional ecology of the ruminant. Ithaca: Cornell University, 1994. 476p.

VIANELLO, R.L.; ALVES, A.R. Meteorologia básica e aplicações. Viçosa, MG: UFV, Imprensa Universitária. 2000. 449p. 